\section{Discussion}

Disorders which could result in a constellation of malformations similar to those seen in this infant include early amnion disruption or short cord sequences, a cytogenetic malformation syndrome, or perhaps Meckel syndrome. No historical or pathological information supports the first, normal cytogenetic studies rule out the second, and the presence of histologically normal kidneys is incompatible with the third. ${ }^{3}$

Heinonen $e a^{1}$ reported a non-significantly raised standardised relative risk for uniform rate malformations of 1.82 for exposures to reserpine and related rauwolfia alkaloids. The list of noted malformations associated with reserpine exposure ${ }^{1}$ includes no examples of a complex similar to that reported here. Similarly, although Sobel ${ }^{4}$ recorded two infant deaths in a series of 15 infants exposed prenatally to reserpine, none had multiple malformations.

In contrast, Goldman and Yakovac ${ }^{2}$ suggested that reserpine exposure (alone or in combination with aspirin) on day 9 or 10 can result in malformations in the rat, including anophthalmia or microphthalmia, thoracoabdominal eventration, cleft lip and palate, central nervous system malformations including encephalocele and cranioschisis, and an increased frequency of late resorptions. Gestational days 9 and 10 in rats are approximately equivalent to days 16 to 24 in humans. ${ }^{5}$

The parallels of timing and of the specific demonstrated malformations are striking. Exposure in the case presented here was at a period analogous to the proposed critical period in rats. The combination of anophthalmia, thoracoabdominal eventration, cleft lip and palate, and central nervous system malformations was present in the rat fetuses and in the human infant described. While in no way proving that the association of reserpine exposure in pregnancy and the multiple malformations seen in this infant are causally related, these parallels do suggest that reserpine exposure may pose specific risks for such multiple malformations in some pregnancies. Additional similar case reports would suggest that this is a 'sentinel case' rather than a fortuitous association.

This infant was initially ascertained through the Wisconsin Stillbirth Service Project supported in part by funding from the Division of Health, Department of Health and Human Services of the State of Wisconsin.

\section{References \\ 1 Heinonen OC, Slone D, Shapiro S. Birth defects and drugs in pregnancy. Littleton, MA: PSG Publishing, 1977:371-6,495. \\ 2 Goldman AS, Yakovac WC. Teratogenic action in rats in reserpine alone and in combination with salicylate and immobi- lization. Proc Soc Exp Biol Med 1965;118:857-62. \\ ${ }^{3}$ Fraser FC, Lytwyn A. Spectrum of anomalies in the Meckel syndrome, or: "Maybe there is a malformation syndrome with at least one constant anomaly". Am J Med Genet 1981;9:67-73. \\ 4 Sobel DE. Fetal damage due to ECT, insulin coma, chlorpro- mazine, or reserpine. Arch Gen Psychiatry 1960;2:606-11. \\ 5 Shepard TH. Catalog of teratogenic agents. 4th ed. Baltimore: Johns Hopkins University Press, 1983:xvii-xix.}

Correspondence and requests for reprints to $\mathrm{Dr}$ Richard M Pauli, Clinical Genetics Center, University of Wisconsin, 1500 Highland Avenue, Madison, Wisconsin 53705, USA.

\title{
Tel Hashomer camptodactyly syndrome: report of a case with myopathic features
}

\author{
M A PATTON*, K D McDERMOT,+ B D.LAKE \\ ${ }^{*}$ Department of Clinical Genetics, Institute of Child Health, 30 Guilford Street, London WC1N 1EH; \\ †Department of Clinical Genetics, Northwick Park Hospital, Watford Road, Harrow, Middlesex; and \\ $\ddagger$ Department of Histopathology, The Hospital for Sick Children, Great Ormond Street, London WC1N 3JH.
}

SUMMARY A child with the Tel Hashomer camptodactyly syndrome is reported. Although muscle weakness and hypoplasia are reported features of this syndrome, further investigation of muscle function has not pre-

Received for publication 26 Octoher 1984 Revised version accepted for publication 21 June 1985 viously been carried out. We report a raised creatine kinase and an abnormal electromyogram and muscle biopsy in this syndrome. The histology of the muscle biopsy shows a wide range fibre diameter in type 1 and type 2 fibres with a relative deficiency of type $2 b$ fibres. It is suggested that this condition may be primarily a myopathy. 
A specific syndrome with camptodactyly, short stature, scoliosis, a characteristic facial appearance, and muscle hypoplasia was first described by Goodman et $a l^{1}$ in Israel in 1972. It was subsequently described as the Tel Hashomer camptodactyly syndrome and was reported in two other sib pairs. ${ }^{23}$ Autosomal recessive inheritance was suggested by the presence of consanguinity in these reports. Although muscle hypoplasia has been a clinical feature, electrophysiological or histological examination of the muscle has not previously been reported.

\section{Case report}

The proband was the third child of unrelated parents (fig 1). Her mother was English and her father, who was adopted, was of Anglo-Asian origin. There was no family history of camptodactyly or muscle weakness.

The pregnancy had been uneventful and delivery was at term with normal birth weight. Initially she was rather obese, but by 2 years she had become thin and her parents were concerned that she was not gaining weight. She sat up unaided at 8 months and walked at 18 months. At 5 years, she was noted to be slower than her friends at running and was unable to hop. Her mental development has been normal.

On examination at 4 years of age her height was $97.5 \mathrm{~cm}$ (10th centile) and weight was $10.2 \mathrm{~kg}$ (below the 3 rd centile). She had facial asymmetry with a broad forehead, prominent nasal bridge, long philtrum, and small mouth (fig 2). She had a narrow, high arched palate with chest asymmetry and a lumbar lordosis was present on standing. Rotation of the neck to the right was reduced, although there was no shortening of the sternomastoid muscle. Increased extension at the elbow was present. The fingers were long and thin. Camptodactyly was present in the third, fourth, and fifth fingers on the left and the fifth finger on the right (fig 3). There

\section{I}

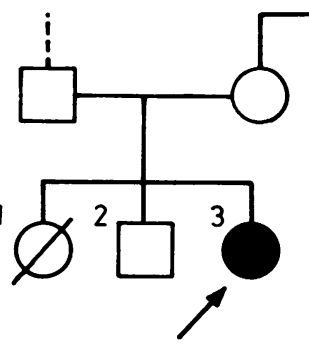

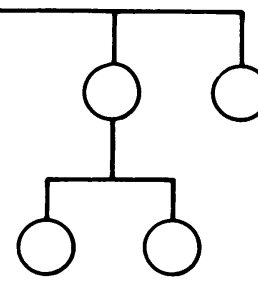

FIG 1 Family pedigree. II.1 died in road traffic accident, I.I was adopted and knows no details of his family. was minimal soft tissue syndactyly. The interphalangeal creases were decreased or absent on the affected fingers. There was a generalised decrease in muscle bulk. Muscle tone and tendon reflexes were normal.

Muscle strength was generally reduced but more marked in the truncal muscles. There was winging of the scapulae and significant weakness of the neck flexors.

Investigations at 5 years of age, showed a normal blood count, urea and electrolytes, liver function

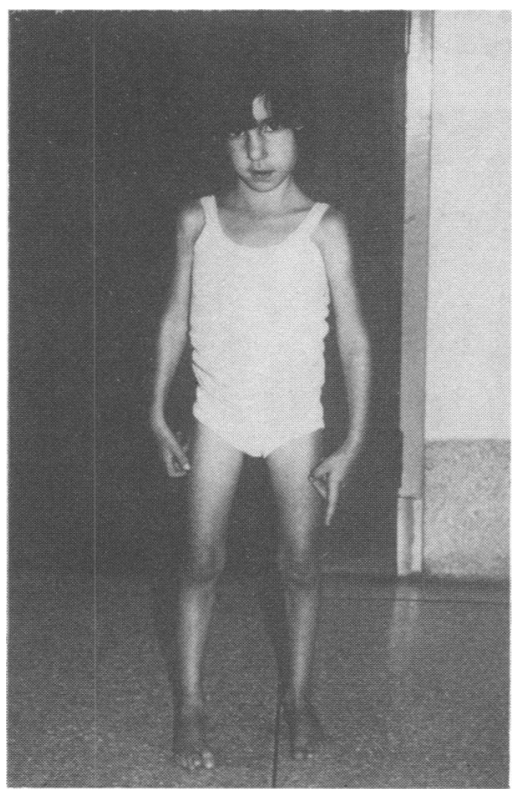

FIG 2 The patient aged 4 years. Facial and body asymmetry, broad nose, and camptodactyly are present.
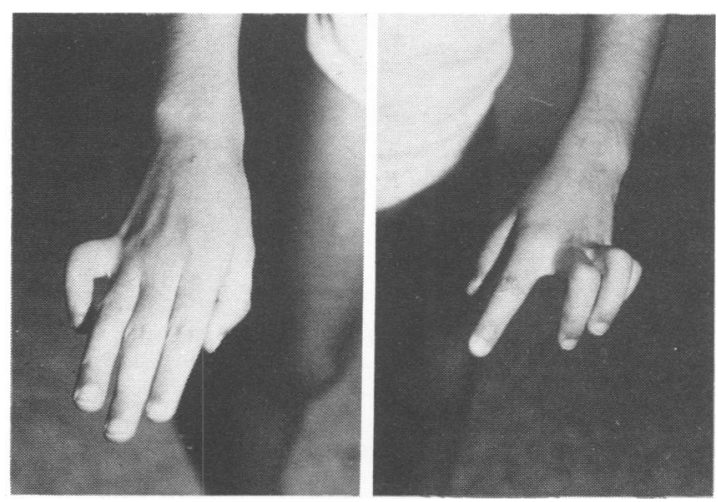

FIG 3 Camptodactyly of fifth finger on right and third, fourth, and fifth fingers on left. 
tests, calcium, amino acids, and karyotype. The electrocardiograph and echocardiogram were normal. The serum creatine kinase was measured using a method optimal for the skeletal muscle isoenzyme (Boehringer Mannheim No 1811 188) and was found to be $175 \mathrm{U} / \mathrm{l}$ (normal age matched range up to 130 $\mathrm{U} / \mathrm{l})$. Motor and sensory nerve conduction velocity was normal (left peroneal nerve $45 \mathrm{~m} / \mathrm{s}$, left sural nerve $44 \mathrm{~m} / \mathrm{s}$ ). Electromyographic sampling of the right extensor digitorum brevis showed polyphasic action potentials with an increased incidence of brief high frequency components. These changes suggested a chronic myopathy. Muscle biopsy (fig 4) from the left quadriceps showed a wide range in the

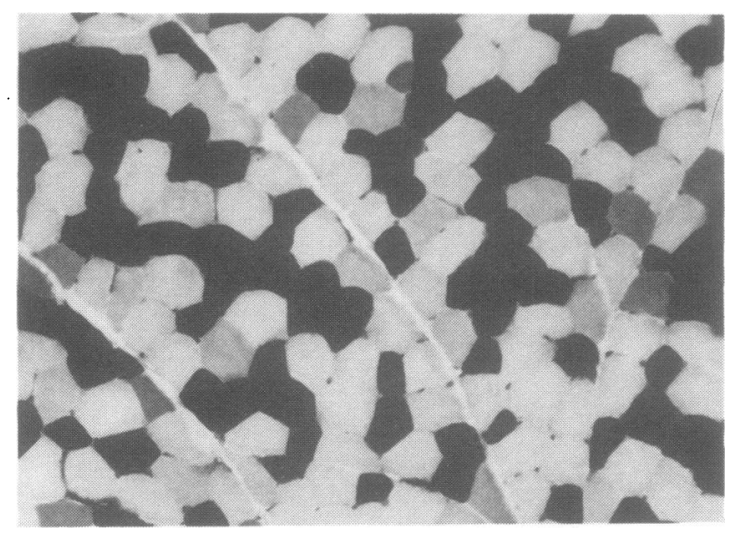

FIG 4 Muscle biopsy: ATPase preparation after preincubation at $\mathrm{pH} 4.3$ showing variation in fibre size of type $I$ (dark) and type $2 a$ (light) fibres. Type $2 b$ fibres (intermediate) are few in number.

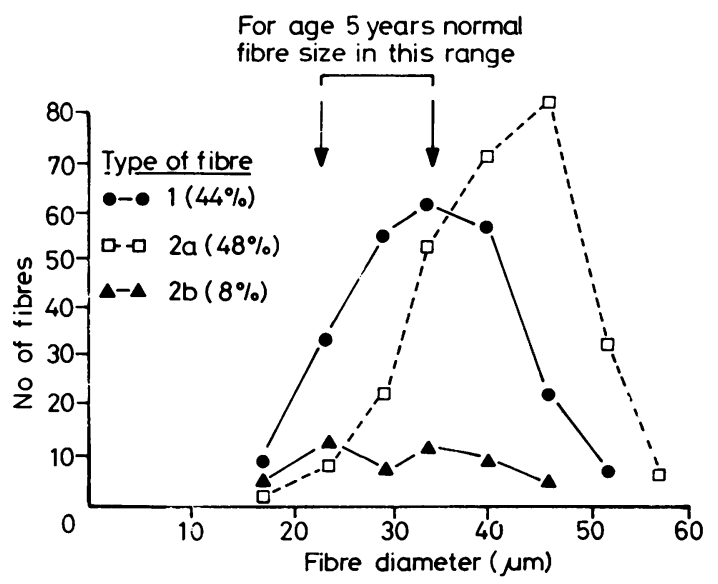

FIG 5 Distribution of muscle fibre size in muscle biopsy from patient. A total of 569 fibres was analysed. The normal age matched range of fibre size is indicated. diameters of type 1 and 2 fibres with a relative deficiency of type $2 b$ fibres. Occasional moth eaten fibres were present. Statistical analysis was carried out on 569 fibres in the photomicrograph. There were $44 \%$ type 1 fibres, $48 \%$ type 2 a fibres, and $8 \%$ type $2 \mathrm{~b}$ fibres. The mean fibre size and standard deviation for type 1 was $33.6 \pm 8.0 \mu \mathrm{m}$, for type $2 \mathrm{a}$ $40 \cdot 8 \pm 7 \cdot 6 \mu \mathrm{m}$, and for type $2 \mathrm{~b} 31 \cdot 4 \pm 8 \cdot 3 \mu \mathrm{m}$. The distribution of fibre size is illustrated in fig 5 with the normal age matched range of fibre size.

\section{Discussion}

This report confirms the phenotypic appearance of the Tel Hashomer camptodactyly syndrome. The facial appearance in the reported cases has been strikingly similar despite different ethnic origins. The facial asymmetry, prominent forehead, broad nasal bridge, and small mouth seem to be the most notable features.

The camptodactyly involves the fingers on the ulnar side of the hand. There is flexion at the proximal and distal interphalangeal joints with extension at the metacarpal phalangeal joint. The camptodactyly was present at birth and probably developed before 11 weeks' gestation. It is suggested ${ }^{4}$ that the thenar and transverse creases of the hand develop before spontaneous hand movements occur in utero at $11 \frac{1}{2} 2$ weeks and that the interphalangeal creases develop secondarily to hand movements around that time. This hypothesis is supported by the fact that the absent or decreased interphalangeal creases in our patient were most marked on the contracted fingers. Loss of interphalangeal creases has been reported in other cases of camptodactyly. ${ }^{5}$

Previous reports of the Tel Hashomer camptodactyly syndrome have stressed the reduction of muscle bulk and all have had winging of the scapulae. There has not been symptomatic weakness athough the first pair of sibs described by Goodman et al ${ }^{1}$ were unable to take part in strenuous sport and our patient was unable to run as fast as her peers. Electromyography or muscle biopsy has not previously been carried out in this syndrome.

In our patient there was a raised creatine kinase, electromyographic evidence of the myopathy, and on histology an abnormality of fibre size. The pattern differs from congenital fibre type disproportion myopathy as the variation is not specifically a reduction in the size of type 1 fibres, but increased range of size of both type 1 and type 2 fibres without hypotrophy or atrophy. The histological picture does not match any recognised myopathy. It may represent an embryological failure in muscle development rather than a progressive muscle disease. 
Many features of this syndrome could be explained by an underlying myopathy. In congenital fibre type disproportion, short stature, contractures, scoliosis, and high arched palate were reported in a review by Cavanagh et al..$^{6}$ In nemaline myopathy skeletal abnormalities and reduced muscle bulk are well recognised. ${ }^{?}$

Further investigation of muscle function in other patients with this syndrome is likely to be rewarding.

We would like to thank Drs J Wilson and J Payan for their help in investigating this patient, and $\mathrm{Dr} S$ Ware for referring the patient to our clinic. Dr M A Patton is supported by a Child Health Research Fund Fellowship.

\footnotetext{
References

${ }^{1}$ Goodman RM, Katznelson MB. Manor E. Camptodactyly: occurrence in two genetic syndromes and its relationship to other syndromes. J Med Genet 1972:9:203-12.
}

- Goodman RM. Katznelson MB. Hertz M. Katznelson A. Camptodactyly, with muscular hypoplasia, skelctal dysplasia and abnormal palmar creases: Tel Hashomer camptodactyly syndrome. J Med Genet 1976:13:136-41.

${ }^{3}$ Gollop TR. Colletto GMDD. The Tel Hashomer camptodactyly syndrome in a consanguincous Brazilian family. Am J Med Genet 1984:17:399-406.

+ Schaumann B. Alter M. Dermatolglyphics in medical disorders. Chap 5. Berlin: Springer-Verlag. 1976:103-29.

5 Popich GA. Smith DW. The genesis and significance of digital and palmar hand creases: preliminary report. $J$ Pediatr 1970;77:1017-23.

" Cavanagh NPC. Lake BD. McMeniman P. Congenital fibre type disproportion myopathy: a histological diagnosis with an uncertain clinical outlook. Arch Dis Child 1979:54:735-43.

${ }^{7}$ Dubowitz V. Muscle disorders of childhood. Philadelphia: Saunders, 1978 .

Correspondence and requests for reprints to $\mathrm{Dr}$ M A Patton, Department of Clinical Genetics, Institute of Child Health, 30 Guilford Street, London WC1N 1EH.

\title{
A male infant with the Catel-Manzke syndrome and dislocatable knees
}

\author{
E M THOMPSON*, R M WINTER ${ }^{*}$, AND M J H WILliAMS \\ *Clinical Genetics Unit, The Hospital for Sick Children, Great Ormond Street, London WC1N 3JH; \\ †Division of Inherited and Metabolic Disease, Clinical Research Centre, Watford Road, Harrow, Middlesex \\ HAI 3UJ; and $¥$ Department of Paediatrics, Watford General Hospital, Shrodells Wing, Vicarage Road, \\ Watford, Herts WD1 $8 H B$.
}

SUMmary A male infant is described with severe micrognathia and bilateral duplication of the proximal phalanges of the index fingers, an association which is characteristic of the Catel-Manzke syndrome. In addition, he had dislocatable knees, which have not been described in this disorder before.

In 1966, Manzke ${ }^{1}$ described in detail a male infant originally reported by Catel. ${ }^{2}$ The child had the Pierre Robin sequence with micrognathia, cleft palate and glossoptosis, associated with an accessory bone at the base of each index finger. In 1982, Sundaram $e t t^{3}$ presented another similar patient and reviewed seven others from published reports, including the original case. They first used the name Catel-Manzke syndrome to describe the disorder. A patient with the same features was also described by

Received for publication 4 May 1985

Revised version accepted for publication 16 July 1985
Silengo et al. ${ }^{4}$ All patients have been males and five have had congenital heart defects. The inheritance pattern is uncertain, with the suggestion of an affected sib $^{5}$ and of affected family members in three generations. ${ }^{6}$

We present another case, also a male, with significant dislocations of the knees.

\section{Case report}

The patient was born at 35 weeks' gestation by caesarian section because of maternal preeclampsia. The birth weight was $2.0 \mathrm{~kg}$ (3rd to 10 th centile) and no resuscitation was required initially. Abnormalities noted at birth included severe micrognathia, a high arched, but intact palate, and marked pectus excavatum. The index fingers were short and their proximal phalanges were broad and deviated radially (fig 1$). X$-rays revealed two small bones at the base of both index fingers, interpreted as duplication of the proximal phalanges, and shortened second metacarpals and bilateral clino- 